\title{
Epidural abscess and feculent meningitis secondary to stercoral ulcer rupture
}

\author{
Christopher E Uy, ${ }^{1}$ Shi Yuan Jiang, ${ }^{2}$ Melanie C M Murray ${ }^{3,4,5}$
}

${ }^{1}$ Department of Neurology, University of British Columbia (UBC), Vancouver, British Columbia, Canada

${ }^{2}$ Department of Medicine, UBC, Vancouver, British Columbia, Canada

${ }^{3}$ Division of Infectious Disease Department of Medicine, UBC, Vancouver, British Columbia, Canada

${ }^{4}$ Women's Health Research Institute, BC Women's Hospital, Vancouver, British Columbia, Canada

${ }^{5}$ Oak Tree Clinic, BC Women's Hospital, Vancouver, British Columbia, Canada

\section{Correspondence to}

Dr Melanie C M Murray, Melanie.Murray@cw.bc.ca

Accepted 17 December 2014
To cite: Uy CE, Jiang SY Murray MCM. BMJ Case Rep Published online: [please include Day Month Year] doi:10.1136/bcr-2014207858

CrossMark

\section{DESCRIPTION}

This 68-year-old Caucasian male presented with fever of $39.8^{\circ} \mathrm{C}$, rigours, hypotension, urinary retention and 2 weeks of abdominal pain. Medical background included colonisation with methicillinresistant Staphylococcus aureus (MRSA) and vancomycin-resistant enterococci (VRE), hypertension, remote ischaemic stroke, coronary bypass, peripheral vascular disease with toe amputation and anterior resection 9 months prior for rectosigmoid mass (benign tubulovillous adenoma).

Abdominal/pelvic CT demonstrated severe faecal impaction and focal perforation at the posterolateral rectosigmoid junction. A large collection posterior to the perforation extended into the presacral musculature. Debris and gas bubbles
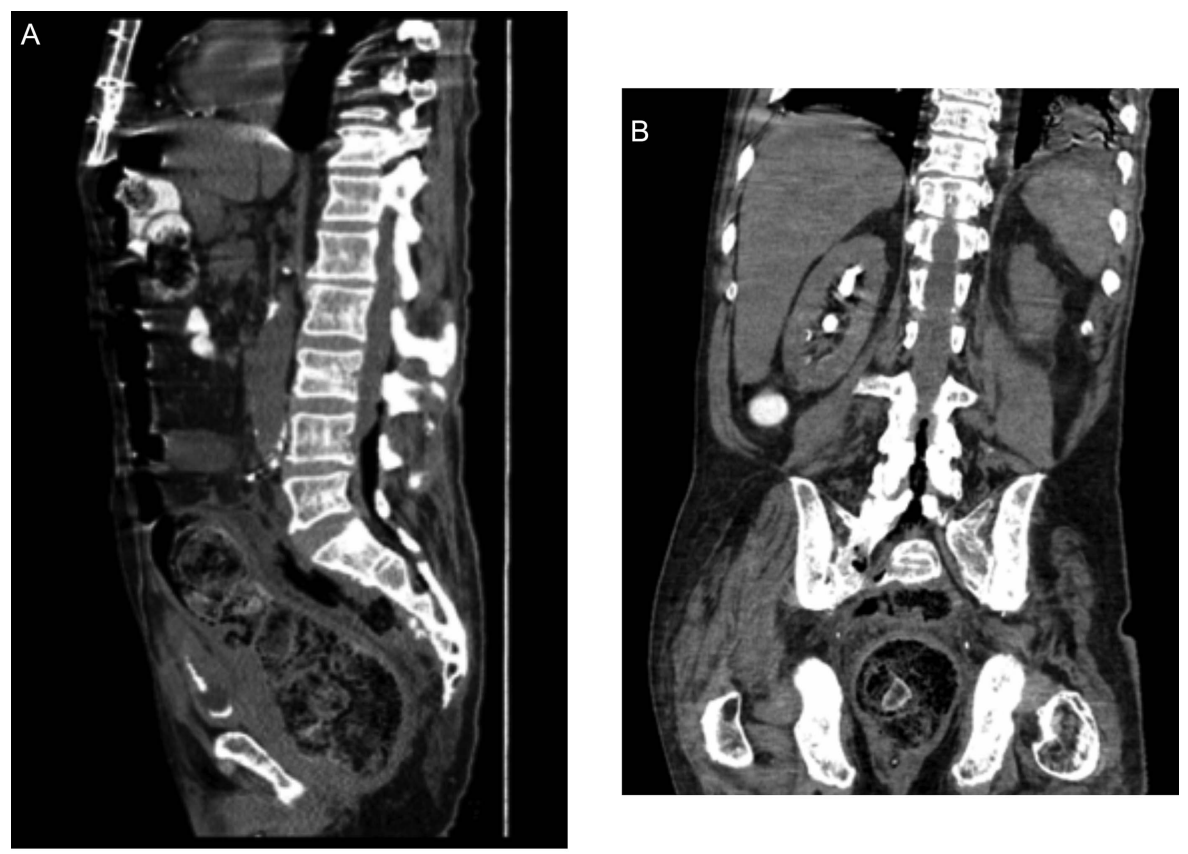

further extended into the epidural space at L3 (figure 1A-C). Subsequent MRI confirmed intraspinal gas, sacral osteomyelitis and posterior L3 epidural abscess extending inferiorly into the sacrum.

Urgent Hartmann's resection revealed a stercoral ulcer with no evidence of diverticulitis or malignancy. The presacral collection of stool and pus was evacuated. Blood cultures grew Escherichia coli susceptible to fluoroquinolones, piperacillin and carbapenems. No valvular abnormalities were seen on echocardiogram. Although meropenem was started preoperatively, the intensive care team changed antibiotics to piperacillin-tazobactam for intra-abdominal sepsis. By postoperative day two, infectious diseases was consulted for persistent fever, worsening shock and depressed level of consciousness. Examination

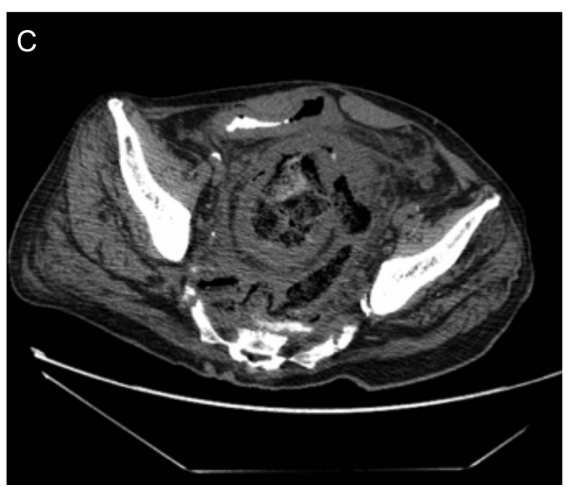

Figure 1 (A) Sagittal section. CT scan (sagittal section) showing sigmoid colon thickening, free air, presacral collection and presence of air in the epidural space. (B) Coronal section. CT scan (coronal view) showing thickened sigmoid colon, presacral collection and tracking of air through the neural foramen and into the epidural space. (C) Horizontal view. CT scan (horizontal) showing perforation of the sigmoid colon the site of previous anastomosis. 


\section{Learning points}

- Fecal impaction can lead to rare but fatal complications such as rupture of stercoral ulcer, a pressure ulcer caused by fecaloma; only 137 cases have been reported in the literature from 1894 to 2011 .

- Although piperacillin-tazobactam is the antibiotic of choice for polymicrobial infection of gastrointestinal source, meropenem was chosen for superior cerebrospinal fluid (CSF) penetration. ${ }^{2}$ Linezolid and fluconazole were also selected for their CSF pharmacokinetics over alternative agents when expanding coverage against vancomycin-resistant enterococci (VRE) and methicillin-resistant Staphylococcus aureus (MRSA) and yeast, respectively. ${ }^{2}$ In addition to choosing antibiotics based on suspected organisms, CSF penetration must be considered when central-nervous system involvement is suspected based on clinical findings or investigations.

- Reports in the literature of feculent meningitis from contiguous spread are predominantly bacterial, and poymicrobial in nature. ${ }^{3}$ Given that this patient was critically ill and meningitis secondary to VRE, MRSA or yeast would likely have resulted in death, fluconazole and linezolid were added empirically. revealed prominent nuchal rigidity with positive Kernig and Brudzinski signs. Given his clinical meningitis and radiographic evidence of faecal contamination, meropenem, linezolid and fluconazole were instituted for wider coverage against MRSA, VRE and yeast. He defervesced and stabilised within $24 \mathrm{~h}$. Repeat CT after 2 months of therapy demonstrated resolution of intraspinal gas and abscess but persistent sacral osteomyelitis.

Acknowledgements The authors would like to thank the patient involved for his willingness to share this case so that in his words, "No one else ever need become this ill from constipation".

Contributors CEU was the resident physician who saw the patient in consultation, obtained consent and wrote the case report. SYJ was the senior resident physician on the team and helped to write the report. MCMM was the attending physician on the infectious disease service and oversaw both treatment of the patient and write up of the case report.

Competing interests None.

Patient consent Obtained.

Provenance and peer review Not commissioned; externally peer reviewed.

\section{REFERENCES}

1 Chakravartty S, Chang A, Nunoo-Mensah J. A systematic review of stercoral perforation. Colorectal Dis 2013;15:930-5.

2 Nau R, Sörgel F, Eiffert H. Penetration of drugs through the blood-cerebrospinal fluid/ blood-brain barrier for treatment of central nervous system infections. Clin Microbiol Rev 2010;23:858-83.

3 Garcia-Lechuz J, Hernangomez S, San Juan R, et al. Feculent meningitis: polymicrobial meningitis in colorectal surgery. Diagn Microbiol Infect Dis 2000;38:169-70.

Copyright 2015 BMJ Publishing Group. All rights reserved. For permission to reuse any of this content visit

http://group.bmj.com/group/rights-licensing/permissions.

BMJ Case Report Fellows may re-use this article for personal use and teaching without any further permission.

Become a Fellow of BMJ Case Reports today and you can:

- Submit as many cases as you like

- Enjoy fast sympathetic peer review and rapid publication of accepted articles

- Access all the published articles

- Re-use any of the published material for personal use and teaching without further permission

For information on Institutional Fellowships contact consortiasales@bmjgroup.com

Visit casereports.bmj.com for more articles like this and to become a Fellow 